\title{
Performance of a Novel Hydrophobic Mesoporous Material for High Temperature Catalytic Oxidation of Naphthalene
}

\author{
Guotao Zhao, ${ }^{1}$ Zhenxiao Zhao, $^{2}$ Junliang Wu, ${ }^{1}$ and Daiqi Ye \\ ${ }^{1}$ College of Environment and Energy, South China University of Technology, Guangzhou 510006, China \\ ${ }^{2}$ School of Chemistry and Chemical Engineering, Guangxi University, Nanning 530004, China \\ Correspondence should be addressed to Daiqi Ye; cedqye@scut.edu.cn
}

Received 20 May 2014; Accepted 18 June 2014; Published 3 July 2014

Academic Editor: Qingrui Zhang

Copyright (c) 2014 Guotao Zhao et al. This is an open access article distributed under the Creative Commons Attribution License, which permits unrestricted use, distribution, and reproduction in any medium, provided the original work is properly cited.

\begin{abstract}
A high surface area, hydrophobic mesoporous material, MFS, has been successfully synthesized by a hydrothermal synthesis method using a perfluorinated surfactant, SURFLON S-386, as the single template. $\mathrm{N}_{2}$ adsorption and TEM were employed to characterize the pore structure and morphology of MFS. Static water adsorption test indicates that the hydrophobicity of MFS is significantly higher than that of MCM-41. XPS and Py-GC/MS analysis confirmed the existence of perfluoroalkyl groups in MFS which led to its high hydrophobicity. MFS was used as a support for $\mathrm{CuO}$ in experiments of catalytic combustion of naphthalene, where it showed a significant advantage over MCM-41 and ZSM-5. SEM was helpful in understanding why CuO-MFS performed so well in the catalytic combustion of naphthalene. Experimental results indicated that MFS was a suitable support for catalytic combustion of large molecular organic compounds, especially for some high temperature catalytic reactions when water vapor was present.
\end{abstract}

\section{Introduction}

In recent years, more and more efforts have been focused on the catalytic removal of VOC or PAHs in ambient air and industrial emissions $[1,2]$. However, traditional catalyst carriers have pore sizes that are too small to be used effectively in the catalytic combustion of large molecular organic pollutants [3]. Recently, many researchers have studied the catalytic removal process of $\mathrm{VOC}$ and PAHs on various mesoporous materials (refers to the kind of aperture between 2 and $50 \mathrm{~nm}$ porous materials) [4-7]. However, the presence of $\mathrm{H}_{2} \mathrm{O}$ molecules still has significant negative impacts on the decomposition of VOCs under these conditions [8]. Therefore, a popular, near-term research goal has been to develop hydrophobic carrier materials that will reduce the negative impacts of $\mathrm{H}_{2} \mathrm{O}$ on catalytic combustion.

Currently, there are many methods for synthesizing hydrophobic mesoporous materials [9-12]. One of the most promising methods involves the use of fluorine-containing materials $[13,14]$. If the method is optimized, the fluorinecontaining groups are introduced onto the surface, even on the inner surfaces of the framework of the mesoporous materials, which enhances the hydrophobicity of the material [15-17] because of strong electronegativity of the fluorine-containing groups.

This paper presents a new method for synthesizing mesoporous materials using the perfluorinated surfactant SURFLON S-386 (a polymeric perfluorocarboxylic acid) as the single template. The resulting mesoporous material (MFS) has a large surface area, high hydrophobiclity, and excellent hydrothermal stability for use in the catalytic combustion of naphthalene.

\section{Experimental}

2.1. Materials and Catalyst Preparation. SURFLON S-386 (99\%) was received from Asahi Glass Company, Japan. TEOS (98\%) was received from J\&K Scientific Company, China. The chemicals were used without additional purification.

The catalyst was prepared by mixing deionized water $(120 \mathrm{~mL})$ and SURFLON S-386 $(0.8 \mathrm{~g})$ in a $250 \mathrm{~mL}$ beaker. After stirring for $1 \mathrm{~h}$ at $40^{\circ} \mathrm{C}$, a mixture of TEOS $(10 \mathrm{~g})$ and $\mathrm{HCl}(5 \mathrm{~mL})$ was added drop by drop in a period of $30 \mathrm{~min}$ while stirring with a magnetic stirrer. After the mixture was added, the stirring was continuous for about $24 \mathrm{~h}$. The mixture was then transferred into an autoclave and was 


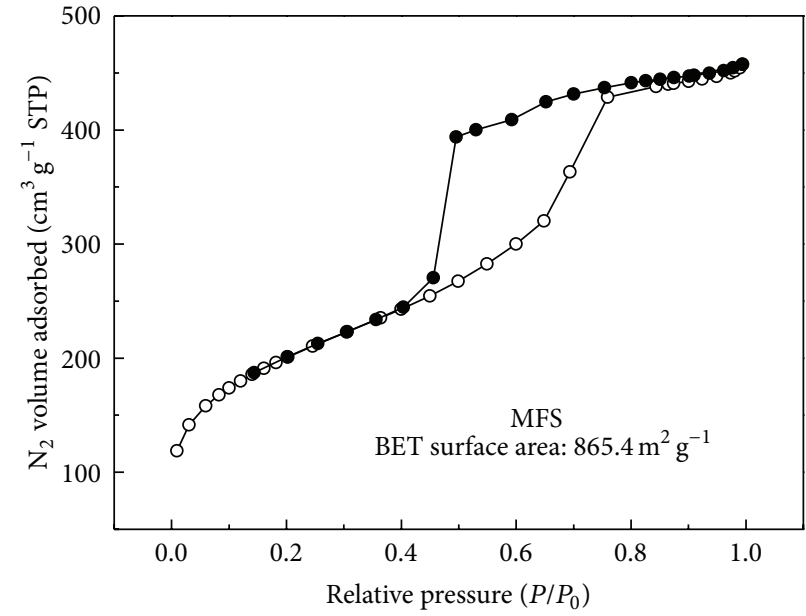

(a)

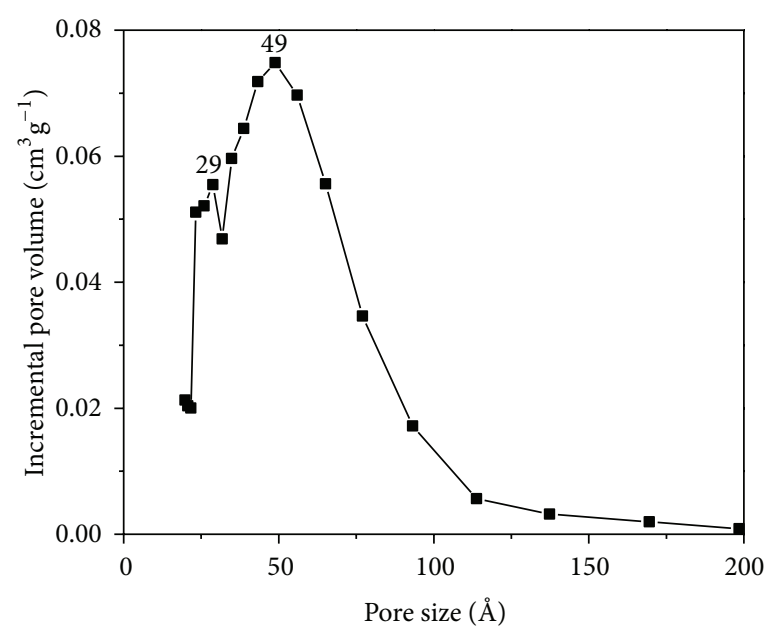

(b)

FIGURE 1: (a) $\mathrm{N}_{2}$ sorption isotherms of MFS $77 \mathrm{~K}$ and (b) pore size distribution in MFS as determined from the $\mathrm{BJH}$ model. $P / P_{o}$ is the ratio of gas pressure $(P)$ to saturation pressure $\left(P_{o}=101.3 \mathrm{kPa}\right)$.

heated for $48 \mathrm{~h}$ at $100^{\circ} \mathrm{C}$. The resulting solid was centrifuged, washed (with water and alcohol), and dried in an oven at $100^{\circ} \mathrm{C}$ for $12 \mathrm{~h}$. The final mesoporous material was calcined at $550^{\circ} \mathrm{C}$ for $6 \mathrm{~h}$ with the average heating rate of $1^{\circ} \mathrm{C} / \mathrm{min}$. The resulting product was marked as MFS.

$\mathrm{CuO}$ was loaded on the MFS via the impregnation method by using $\mathrm{Cu}\left(\mathrm{NO}_{3}\right)_{2} \cdot 3 \mathrm{H}_{2} \mathrm{O}$ [18]. After evaporation and drying, the resulting solid material was calcined at $500^{\circ} \mathrm{C}$ for $4 \mathrm{~h}$. After tableting and screening through with $40 \sim 60$ mesh different concentrations of the catalyst were prepared by using different amounts of $\mathrm{Cu}\left(\mathrm{NO}_{3}\right)_{2} \cdot 3 \mathrm{H}_{2} \mathrm{O}$. These catalysts were noted as $\mathrm{CuO}-\mathrm{MFS}$. The percentage of $\mathrm{CuO}$ ranged from 2 to $25 \%$, expressed as the weight ratio of $\mathrm{W}_{\mathrm{CuO}} / \mathrm{W}_{\text {support }}$.

2.2. Hydrophobicity Test. The hydrophobicities of the MFS samples were measured by the GBT6287-86 method (National Standards, China). The results obtained from the various materials were characterized by static adsorption rate.

2.3. Catalyst Activity Test. The catalytic activity test was performed with a continuous flow fixed-bed reactor with $8 \mathrm{~mm}$ ID, similar to that reported in the literature [19]. In each test run, $100 \mathrm{mg}$ of catalyst was diluted with an appropriate amount of inert quartz beads (40 60 mesh) placed at the center of the reactor, above which a thermocouple was located to monitor the reaction temperatures. To create the stream containing naphthalene, a stream of pure dry air was passed through a U-shaped tube (contain naphthalene) at constant temperature $\left(30^{\circ} \mathrm{C}\right)$ to produce a mixed gas containing a high concentration of naphthalene. The total flow rate was set at $180 \mathrm{~mL} \mathrm{~min}^{-1}$ with a concentration of $300 \mathrm{ppm}$ naphthalene by adjusting the flow rate. The gas hourly space velocity (GHSV) in the tests was kept at $120000 \mathrm{~h}^{-1}$.

An on-line gas chromatograph equipped with a FID detector was used to analyze the concentration of naphthalene in the inlet and outlet gas. Before each measurement, the temperature of the catalytic bed was raised to $200^{\circ} \mathrm{C}$ and stabilized at that temperature until the concentration of naphthalene became constant. No conversion of naphthalene was observed at this temperature. Then the temperature of catalyst bed was raised at $20^{\circ} \mathrm{C} / \mathrm{min}$ until the experimental temperature was reached. Then the export concentration of naphthalene could be analyzed.

2.4. Materials Characterization. The specific surface areas (SSAs) of the catalysts $(0.1-0.3 \mathrm{~g})$ were determined with the BET method using an ASAP 2020 Micropore System (Micromeritics, USA). A vacuum pretreatment with vacuum at $300^{\circ} \mathrm{C}$ for $2 \mathrm{~h}$ was followed by nitrogen adsorption at $-196^{\circ} \mathrm{C}$. TEM (transmission electron microscopy) images were obtained using JEM-2010HR transmission electron microscope (Japan).

The elements and their valances were measured by XPS (XML Paper Specification) using VG Multilab 2000 spectrometer (Germany) equipped with a hemispherical electron analyzer and $\mathrm{Mg}$ Ka radiation source $(h \nu=1253.6 \mathrm{eV})$. All binding energies were referenced to the $\mathrm{C}_{1 \mathrm{~s}}$ line at $284.6 \mathrm{eV}$, which provided an accuracy of $\pm 0.48 \mathrm{eV}$ within full scanning of $0 \sim 1000 \mathrm{eV}$.

Py-GC/MS (pyrolysis-gas chromatography/mass spectrometry) analysis was carried out using a GC/MS-QP2010 PLUS pyrolysis gas chromatograph (Shimadzu, Japan) with a CDS (USA) cracker. SEM (scanning electron microscopy) images were obtained on a Philips FEIXL-30, operated with a $10 \mathrm{kV}$ accelerating voltage after gold deposition.

\section{Results and Discussion}

\subsection{Samples Characterization}

3.1.1. Nitrogen Adsorption. MFS sample was subjected to $\mathrm{N}_{2}$ adsorption studies [20]. The specific surface area was calculated according to the Brunauer-Emmett-Teller (BET) 


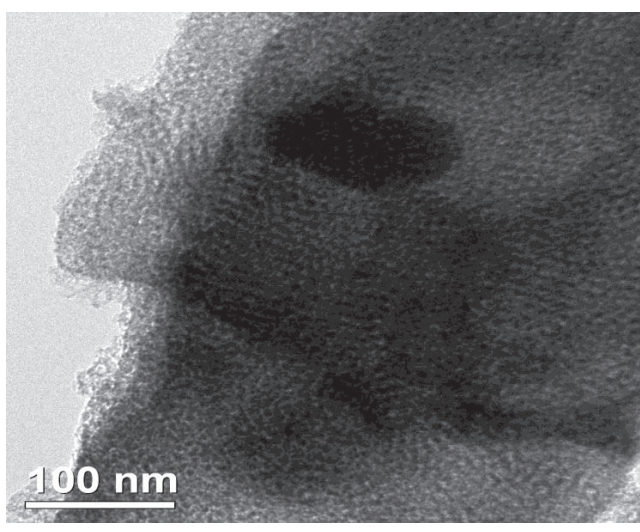

(a)

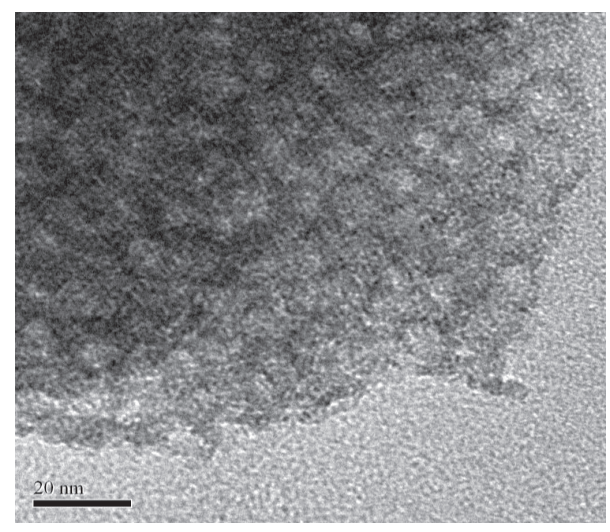

(b)

FIgURE 2: TEM ((a) and (b)) images of the synthesized MFS.

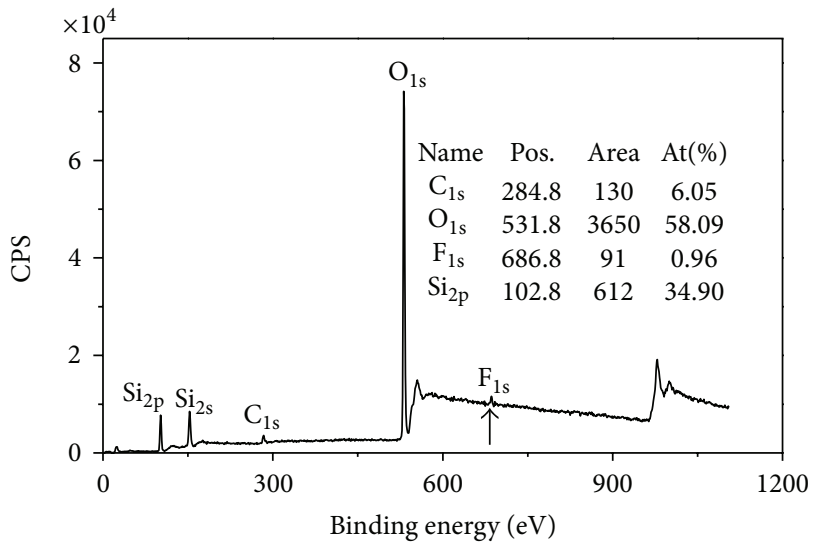

(a)

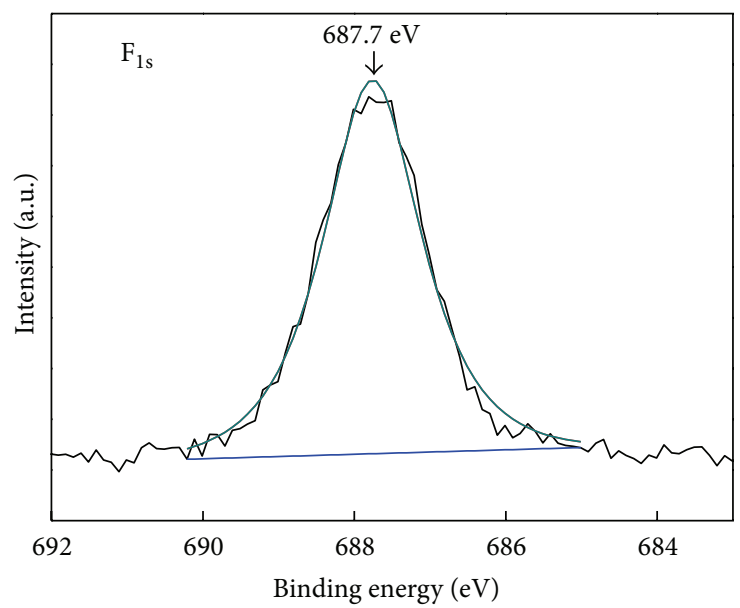

(b)

FIGURE 3: (a) XPS full spectra of MFS and (b) XPS spectra of $F_{1 \mathrm{~s}}$ in MFS.

method and the average pore diameter was obtained according to the Barrett-Soyner-Halenda (BJH) method. A typical nitrogen adsorption isotherm is shown in Figure 1(a). Its BET surface area, Langmuir surface area, and pore volume were calculated to be $865.4 \mathrm{~m}^{2} \mathrm{~g}^{-1}, 1205.1 \mathrm{~m}^{2} \mathrm{~g}^{-1}$, and $0.74 \mathrm{~cm}^{3} \mathrm{~g}^{-1}$, respectively. Its mesopore area and mesopore volume were $928.0 \mathrm{~m}^{2} \mathrm{~g}^{-1}$ and $0.7 \mathrm{~cm}^{3} \mathrm{~g}^{-1}$. In BJH differential pore volume plot, two sharp peaks are observed at about $2.9 \mathrm{~nm}$ and $4.9 \mathrm{~nm}$ for the MFS (Figure 1(b)), indicating a very narrow pore size for this mesoporous material.

3.1.2. Transmission Electron Microscopy (TEM). Figures 2(a) and 2(b) show the TEM images of the MFS sample [20]. Some clear amorphous channel can be seen on the surface of the material. The light and dark stripes that are typical of mesoporous structures can also be observed in the MFS [16].

3.1.3. XML Paper Specification (XPS). Figure 3(a) shows the XPS full spectrum of MFS, which shows the electron energy states of five elements: $\mathrm{Si}_{2 \mathrm{~s}}, \mathrm{Si}_{2 \mathrm{p}}, \mathrm{C}_{1 \mathrm{~s}}, \mathrm{O}_{1 \mathrm{~s}}$, and $\mathrm{F}_{1 \mathrm{~s}}$, and content of fluoride element accounts for about $1 \%$ (At\%).

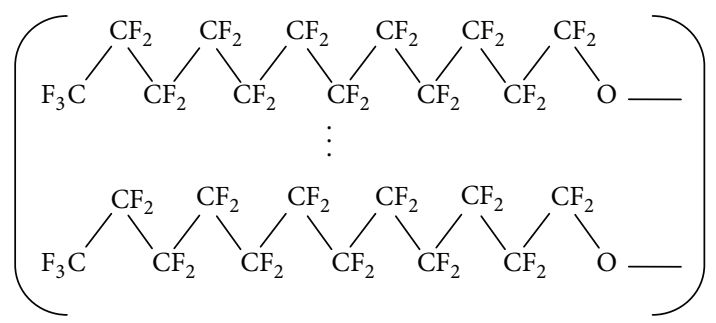

FIGURE 4: Molecular structure of SURFLON S-386.

Figure 3(b) shows the XPS spectrum of $F_{1 s}$. F species were detected centered around $687.7 \mathrm{eV}$ and are attributed to the $-\mathrm{CF}_{x}$ bonds [21] which are related to the molecular structure of SURFLON S-386 (Figure 4). Therefore, it implies that a portion of the SURFLON S-386 fragments remain on the surface of MFS after calcination.

3.1.4. Pyrolysis-Gas Chromatography/Mass Chromatogram (PY-GC/MS). Pyrolysis-gas chromatography/mass spectrometry (Py-GC/MS) was employed to obtain structural 
TABLE 1: Main pyrolytic products of MFS according to Py-GC/MS.

\begin{tabular}{|c|c|c|c|c|}
\hline Number & R. time (min) & Compound (matching) & Molecular weight & Peak \\
\hline 1 & 1.575 & Carbon dioxide & 44 & $\mathrm{a}$ \\
\hline 2 & 1.742 & Propanone & 58 & $\mathrm{~b}$ \\
\hline 3 & 1.950 & $\begin{array}{c}\text { 1-Decene, } 3,3,4,4,5,5,6,6,7,7,8,8,9,9,10,10 \\
\text { 10-heptadecafluoro- }\end{array}$ & 77 & c \\
\hline 4 & 2.100 & alpha-Methylfuran & 82 & - \\
\hline 5 & 2.308 & 2-Propanone & 74 & - \\
\hline 6 & 2.967 & Propylene glycol & 76 & - \\
\hline 7 & 3.208 & Succinaldehyde & 86 & - \\
\hline 8 & 3.892 & Heptane & 112 & - \\
\hline 9 & 4.050 & 2-Cyclopenten-1-one & 82 & - \\
\hline 10 & 4.383 & $\begin{array}{c}\text { 1-Decanol,3,3,4,4,5,5,6,6,7,7,8,8,9,9,10,10, } \\
\text { 10-heptadecafluoro- }\end{array}$ & 464 & $\mathrm{~d}$ \\
\hline
\end{tabular}

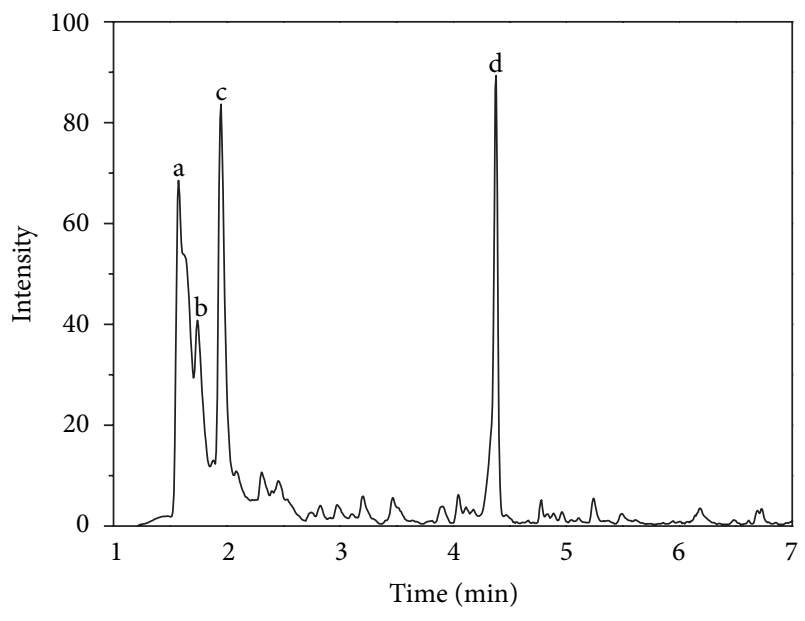

FIGURE 5: PY-GC/MS chromatogram of MFS.

information about MFS. The analytical procedure used in this study is similar to that reported previously [22]. The pyrolysis temperature was set at $800^{\circ} \mathrm{C}$ and held for $10 \mathrm{~s}$ from room temperature, with an average heating rate of $20^{\circ} \mathrm{C} / \mathrm{ms}$. The main pyrolytic products identified are listed in Table 1, and main peaks of the chromatogram are shown in Figure 5. The peak at $1.575 \mathrm{~min}$ is attributed to $\mathrm{CO}_{2}$, a combustion product of organic matter at high temperatures. Peak $\mathrm{c}$ at $1.950 \mathrm{~min}$ is attributed to the fluorine-containing decene according to the MS database, which is likely the residue of the template SURFLON S-386. Peak b at $1.742 \mathrm{~min}$ and other peaks from $2.10-4.05 \mathrm{~min}$ are also ascribed to the fragments of the template or intermediate species generated under high temperature. Peak $\mathrm{d}$ at $4.383 \mathrm{~min}$ is attributed to the fluorine-containing decanol according to MS database, which can be regarded as a new combination of SURFLON S-386 fragments with silicon-hydroxyl on the MFS surface. These findings indicate that fluorine-containing species exist

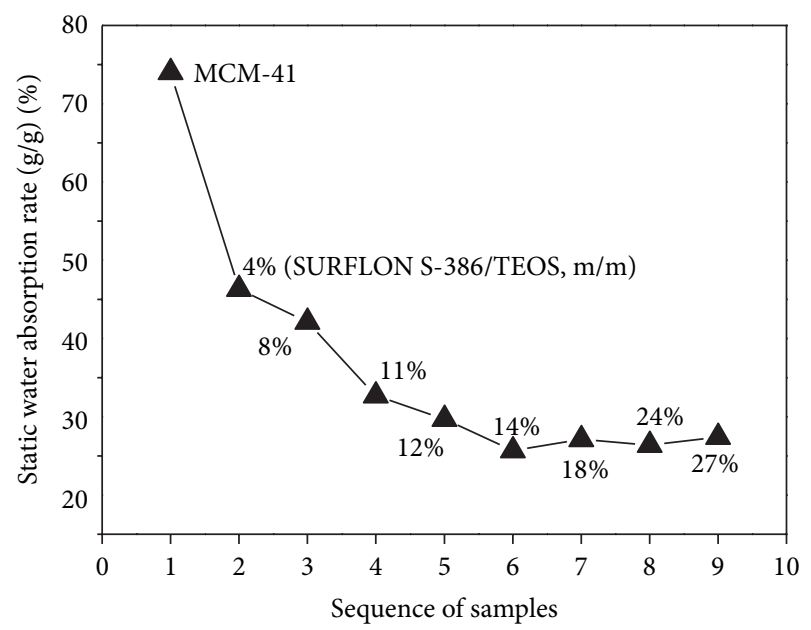

FIgUre 6: Adsorption of static water on MFSs and MCM-41 (100\% humidity).

on the MFS surface, which are a result of SURFLON S-386 fragments remaining on the surface of MFS after calcinations.

3.2. Results of Hydrophobicity Test. A series adsorption of static water tests was conducted to investigate the hydrophobic properties of MFSs and MCM-41. Various MFS samples were synthesized with different amounts of SURFLON S386 ( $\mathrm{g}_{\text {SURFLON S-386 }} / \mathrm{g}_{\text {TEOS }}, \mathrm{m} / \mathrm{m}$ ) used during the process of synthesis. Different materials gave different static water adsorption rates as shown in Figure 6. Static water adsorption rate of MCM-41 is $74 \%\left(\mathrm{~g}_{\text {water }} / \mathrm{g}_{\text {adsorbent }}, \mathrm{m} / \mathrm{m}\right)$, while the adsorption rate of MFS with 4\% SURFLON S-386 is $46.3 \%$. Then adsorption rate starts to decrease with the increase of the dosage. Adsorption rate dropped to $25.7 \%$, when the dosage of SURFLON S-386 increased to 14\%. Adsorption rate did not change significantly with increase of SURFLON S386 dosage. Compared with MCM-41, the largest decrease of adsorption rate for SURFLON S-386 was greater than 


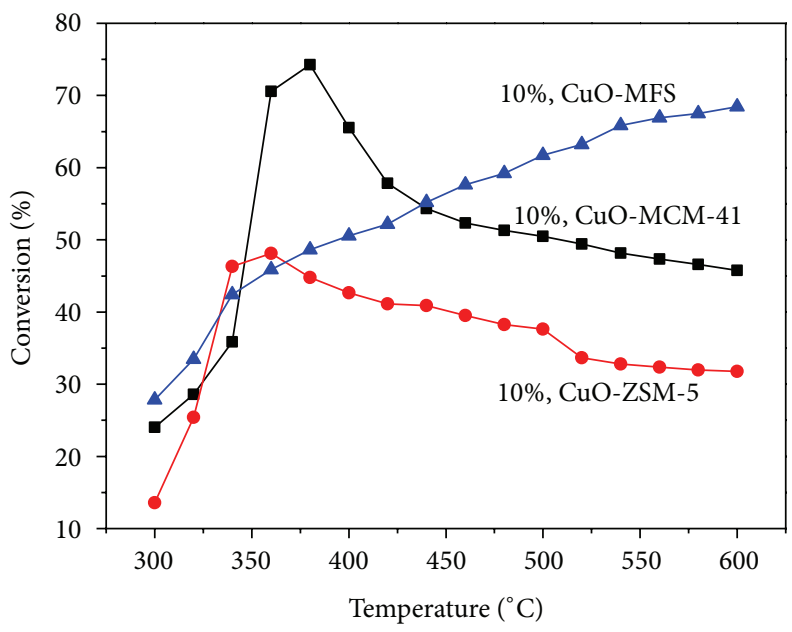

Figure 7: Conversion curves of naphthalene combustion over various materials.

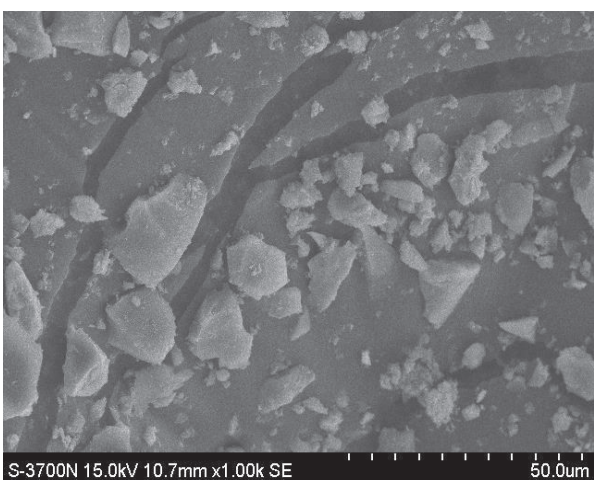

(10\% CuO-MFS-01, before reaction)

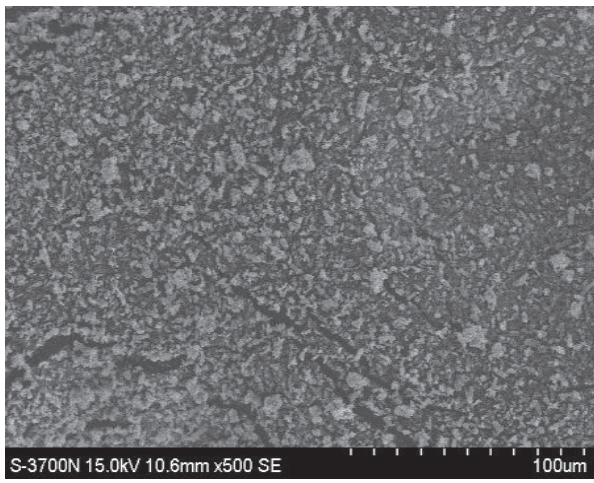

(10\% CuO-ZSM-5-01, before reaction)

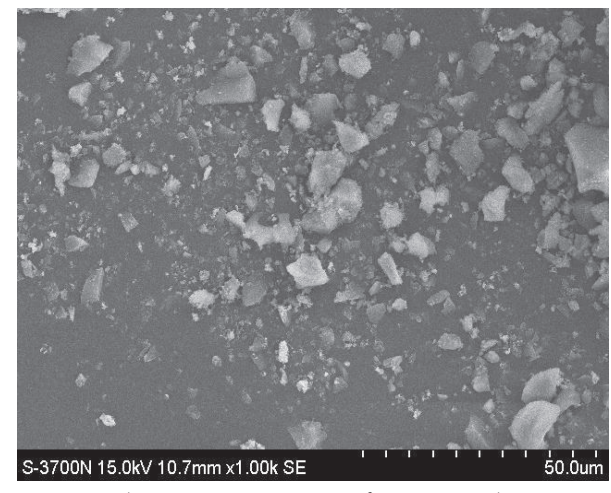

(10\% CuO-MFS-02, after reaction)

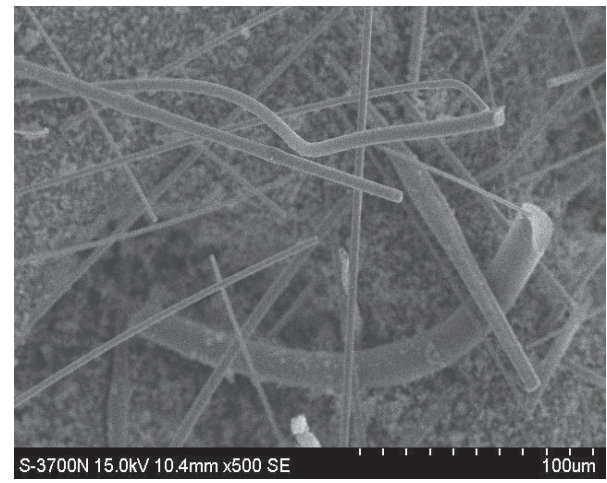

(10\% CuO-ZSM-5-02, after reaction)

Figure 8: SEM of CuO-MFS and CuO-ZSM-5 before reaction and after reaction.

$50 \%$. This means the hydrophobicity of MFS is significantly stronger than that of MCM-41. This behavior may be due to the existence of perfluoroalkyl groups remaining from SURFLON S-386 which reduces the surface tension and reduces the adsorption chances with water.

3.3. Results of Catalytic Performance Experiments. Catalytic combustion of naphthalene has been investigated, and the results are shown in Figures 7-9. Figure 7 shows the results of catalytic combustion of naphthalene with three catalysts:
10\% CuO-ZSM-5, 10\% CuO-MCM-41, and 10\% CuO-MFS at temperatures from $300^{\circ} \mathrm{C}$ to $600^{\circ} \mathrm{C}$.

With $10 \% \mathrm{CuO}-\mathrm{MCM}-41$, the conversion of naphthalene at first increases sharply, reaching a maximum conversion of $74.3 \%$ at $380^{\circ} \mathrm{C}$ and then decreasing at higher temperatures. A possible reason is that the hydrothermal stability of MCM41 decreases at high temperature [23], which leads to the decrease in the conversion of naphthalene. Generally, MCM41 is mainly used as a carrier for catalysts of combustion of small hydrocarbon molecules $[24,25]$. If the temperature 
is higher than $400^{\circ} \mathrm{C}$, the structure of MCM- 41 may be disrupted due to the presence of water vapor.

As for CuO-ZSM-5, its conversion also initially increases sharply, reaching a maximum conversion of $48 \%$ at $386^{\circ} \mathrm{C}$ and then decreasing at higher temperatures. One possible explanation for this behavior is that intermediate products generated in the reaction process block the channels of ZSM-5, which reduce the adsorption capacity for organic compounds, limiting the opportunities for naphthalene to enter the pores of ZSM-5. Hence, ZSM-5 is probably not appropriate for use as a catalyst carrier for catalytic combustion of large molecular organic compounds.

Figure 8 shows the SEM images of $10 \%$ CuO-ZSM- 5 and $10 \% \mathrm{CuO}-\mathrm{MFS}$ before and after reaction. Comparing the paired images for $10 \% \mathrm{CuO}-\mathrm{ZSM} 5-01 \mathrm{~A}$ and for $10 \%$ CuO-ZSM5-02A, it can be seen that many stacked rodlike structures have formed on the surface of catalyst after reaction. The rod-like structure is probably the deposition of coke generated by the decomposition of naphthalene during the conversion process. When the catalytic reaction is going on, the larger incomplete oxidation products of naphthalene have difficulty entering the pores of ZSM-5. After continual accumulation and recombination, the rod-like structures start to form and grow at higher temperature.

In contrast, Figure 8 shows there is no significant change observed on the surface of MFS before and after reaction from the two images of MFS. However, for $10 \% \mathrm{CuO}$ MFS, the conversion of naphthalene increases slowly without maximum within the whole operation temperature range. The maximum conversion of $10 \% \mathrm{CuO}-\mathrm{MFS}$ is lower than $10 \% \mathrm{CuO}-\mathrm{MCM}-41$, which may be due to the strong electronegativity of $\mathrm{F}$, leading to the reduced activity of active species.

The light-off curve of CuO-MFS for catalytic combustion of naphthalene is shown in Figure 9. When the loading reaches $10 \%$, the conversion reaches a maximum at all temperatures. Increasing the $\mathrm{CuO}$ loading further to $20 \%$, results in a decline of the naphthalene conversion, which can be attributed to the agglomeration of the catalyst particles.

\section{Conclusion}

A novel fluorine-containing, high surface area, hydrophobic mesoporous material, MFS, has been successfully synthesized by a hydrothermal synthesis method using a perfluorinated surfactant SURFLON S-386 as the single template. Some perfluoroalkyl groups from the SURFLON S-386 remain on the surface of MFS which leads to a high hydrophobicity of the material. MFS has significant advantages for use in the catalytic combustion of large molecular organic pollutants, especially those found in high temperature flue gases that contain water vapor. These advantages stem from MFS's high hydrophobicity and larger pore diameter. Further work is needed to reduce the negative impacts of fluorine on the catalytic combustion reaction and to improve the naphthalene conversion at lower temperatures.

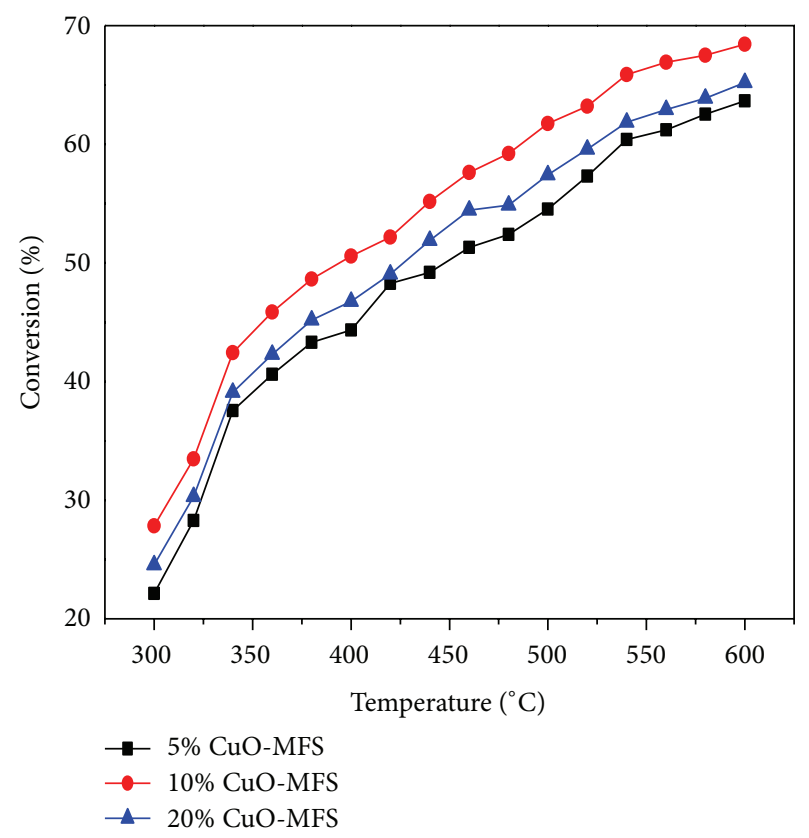

FIGURE 9: Conversion curves of naphthalene combustion over $\mathrm{CuO}$ FS-01.

\section{Conflict of Interests}

The authors declare that there is no conflict of interests regarding the publishing of this paper.

\section{Acknowledgments}

The authors gratefully acknowledge the project supported by the National High Technology Research and Development Program of China (grant no. 2013AA065005) and the National Natural Science Foundation of China (no. 21376090). The project was sponsored by the Scientific Research Foundation of GuangXi University (Grant No. XGZ130963).

\section{References}

[1] X. Y. Wang, Q. Kang, and D. Li, "Catalytic combustion of chlorobenzene over $\mathrm{MnOx}-\mathrm{CeO}_{2}$ mixed oxide catalysts," Applied Catalysis B, vol. 86, no. 3-4, pp. 166-175, 2009.

[2] W. B. Li, J. X. Wang, and H. Gong, "Catalytic combustion of VOCs on non-noble metal catalysts," Catalysis Today, vol. 148, no. 1-2, pp. 81-87, 2009.

[3] H. S. Kim, T. W. Kim, H. L. Koh, S. H. Lee, and B. R. Min, "Complete benzene oxidation over Pt-Pd bimetal catalyst supported on $\gamma$-alumina: influence of Pt-Pd ratio on the catalytic activity," Applied Catalysis A: General, vol. 280, no. 2, pp. 125-131, 2005.

[4] Z. Mu, J. J. Li, H. Tian, Z. P. Hao, and S. Z. Qiao, "Synthesis of mesoporous Co/Ce-SBA-15 materials and their catalytic performance in the catalytic oxidation of benzene," Materials Research Bulletin, vol. 43, no. 10, pp. 2599-2606, 2008.

[5] G. Laugel, J. Arichi, M. Molière, A. Kiennemann, F. Garin, and B. Louis, "Metal oxides nanoparticles on SBA-15: efficient 
catalyst for methane combustion," Catalysis Today, vol. 138, no. 1-2, pp. 38-42, 2008.

[6] Y. S. Xia, H. X. Dai, L. Zhang, J. Deng, H. Hea, and C. T. $\mathrm{Au}$, "Ultrasound-assisted nanocasting fabrication and excellent catalytic performance of three-dimensionally ordered mesoporous chromia for the combustion of formaldehyde, acetone, and methanol," Applied Catalysis B: Environmental, vol. 100, no. 1-2, pp. 229-237, 2010

[7] Z.-J. Wang, Y. Liu, P. Shi, C.-J. Liu, and Y. Liu, "Al-MCM41 supported palladium catalyst for methane combustion: effect of the preparation methodologies," Applied Catalysis B: Environmental, vol. 90, no. 3-4, pp. 570-577, 2009.

[8] Q.-H. Xia, K. Hidajat, and S. Kawi, "Adsorption and catalytic combustion of aromatics on platinum-supported MCM-41 materials," Catalysis Today, vol. 68, no. 1-3, pp. 255-262, 2001.

[9] M. Park, S. S. Park, M. Selvaraj, D. Zhao, and C. Ha, "Hydrophobic mesoporous materials for immobilization of enzymes," Microporous and Mesoporous Materials, vol. 124, no. 1-3, pp. 7683, 2009.

[10] E. Serra, E. Díez, I. Díez, and R. M. Blanco, "A comparative study of periodic mesoporous organosilica and different hydrophobic mesoporous silicas for lipase immobilization," Microporous and Mesoporous Materials, vol. 132, pp. 487-493, 2010.

[11] H. Yamashita, Y. Horiuchi, S. Imaoka, S. Nishio, N. Nishiyama, and K. Mori, "Surface hydrophilic-hydrophobic property on transparent mesoporous silica thin films containing chromium oxide single-site photocatalyst," Catalysis Today, vol. 132, no. 14, pp. 146-152, 2008.

[12] B. Dou, J. Li, Q. Hu et al., "Hydrophobic micro/mesoporous silica spheres assembled from zeolite precursors in acidic media for aromatics adsorption," Microporous and Mesoporous Materials, vol. 133, no. 1-3, pp. 115-123, 2010.

[13] Y. Di, X. J. Meng, S. G. Li, and F. S. Xiao, "Ordering improvement of mesoporous silica materials templated from semi-fluorinated nonionic surfactants by introduction of organic additives," Microporous and Mesoporous Materials, vol. 82, no. 1-2, pp. 121127, 2005.

[14] L. G. Hortiguela, F. Cora, and J. P. Pariente, "Supramolecular assemblies of fluoro-aromatic organic molecules as structure directing agents of microporous materials: different effects of fluorine," Microporous and Mesoporous Materials, vol. 109, pp. 494-504, 2008.

[15] R. García, M. Arranz, T. Blasco, and J. P. Pariente, "Fluorinecontaining organic molecules as structure directing agents in the synthesis of crystalline microporous materials. Part III: Synthesis of all-silica zeolites from fluorine-containing derivatives of 1-benzyl-1-methylpyrrolidinium," Microporous and Mesoporous Materials, vol. 114, no. 1-3, pp. 312-321, 2008.

[16] S. C. Sharma, H. Kunieda, J. Esquena, and C. Rodríguez Abreu, "Phase behavior and preparation of mesoporous silica in aqueous mixtures of fluorinated surfactant and hydrophobic fluorinated polymer," Journal of Colloid and Interface Science, vol. 299, no. 1, pp. 297-304, 2006.

[17] J. L. Blin, N. Henzel, and M. J. Stébé, "Mixed fluorinatedhydrogenated surfactant-based system: preparation of ordered mesoporous materials," Journal of Colloid and Interface Science, vol. 302, no. 2, pp. 643-650, 2006.

[18] T. García, B. Solsona, and S. H. Taylor, "Naphthalene total oxidation over metal oxide catalysts," Applied Catalysis B: Environmental, vol. 66, no. 1-2, pp. 92-99, 2006.

[19] Z. Mu, J. J. Li, Z. P. Hao, and S. Z. Qiao, "Direct synthesis of lanthanide-containing SBA-15 under weak acidic conditions and its catalytic study," Microporous and Mesoporous Materials, vol. 113, no. 1-3, pp. 72-80, 2008.

[20] G. Zhao, Z. Zhao, J. Wu, and D. Ye, "Synthesis of hydrophobic mesoporous material MFS and its adsorption properties of water vapor," Journal of Spectroscopy, vol. 2014, Article ID 965037, 7 pages, 2014

[21] X. Y. Wu, P. Cong, H. Nanao, K. Kobayashi, and S. Mori, "Chemisorption and tribochemical reaction mechanisms of HFC-134a on nascent ceramic surfaces," Langmuir, vol. 18, no. 26, pp. 10122-10127, 2002.

[22] Q. Lu, X. F. Zhu, W. Z. Li, Y. Zhang, and D. Yu. Chen, "On-line catalytic upgrading of biomass fast pyrolysis products," Chinese Science Bulletin, vol. 54, no. 11, pp. 1941-1948, 2009.

[23] P. A. Jalil, "Investigations on MCM-41 as a fume catalytic incinerator: a heptane case study," Fuel Processing Technology, vol. 85, no. 11, pp. 1317-1332, 2004.

[24] W. B. Li, M. Zhuang, and J. X. Wang, "Catalytic combustion of toluene on $\mathrm{Cu}-\mathrm{Mn} / \mathrm{MCM}-41$ catalysts: influence of calcination temperature and operating conditions on the catalytic activity," Catalysis Today, vol. 137, no. 2-4, pp. 340-344, 2008.

[25] E. V. Makshina, N. S. Nesterenko, S. Siffert, E. A. Zhilinskaya, A. Aboukais, and B. V. Romanovsky, "Methanol oxidation on LaCo mixed oxide supported onto MCM-41 molecular sieve," Catalysis Today, vol. 131, no. 1-4, pp. 427-430, 2008. 

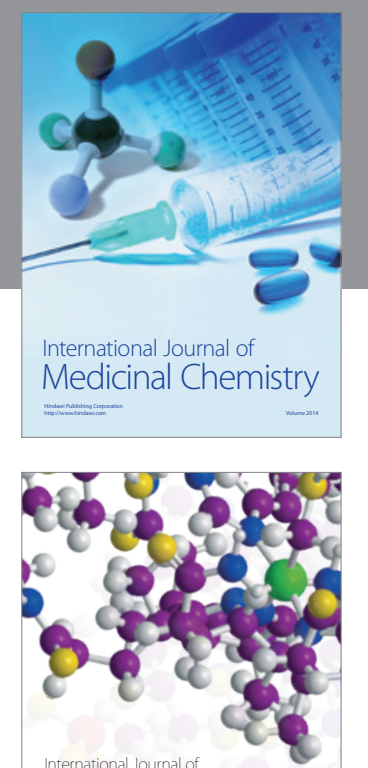

\section{Carbohydrate} Chemistry

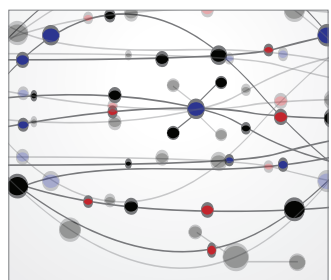

The Scientific World Journal
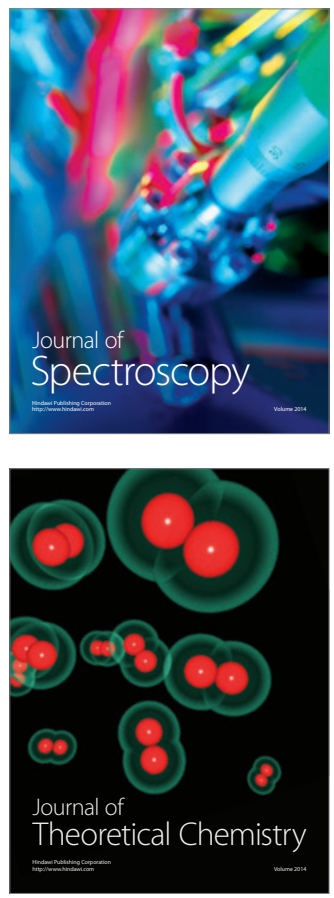
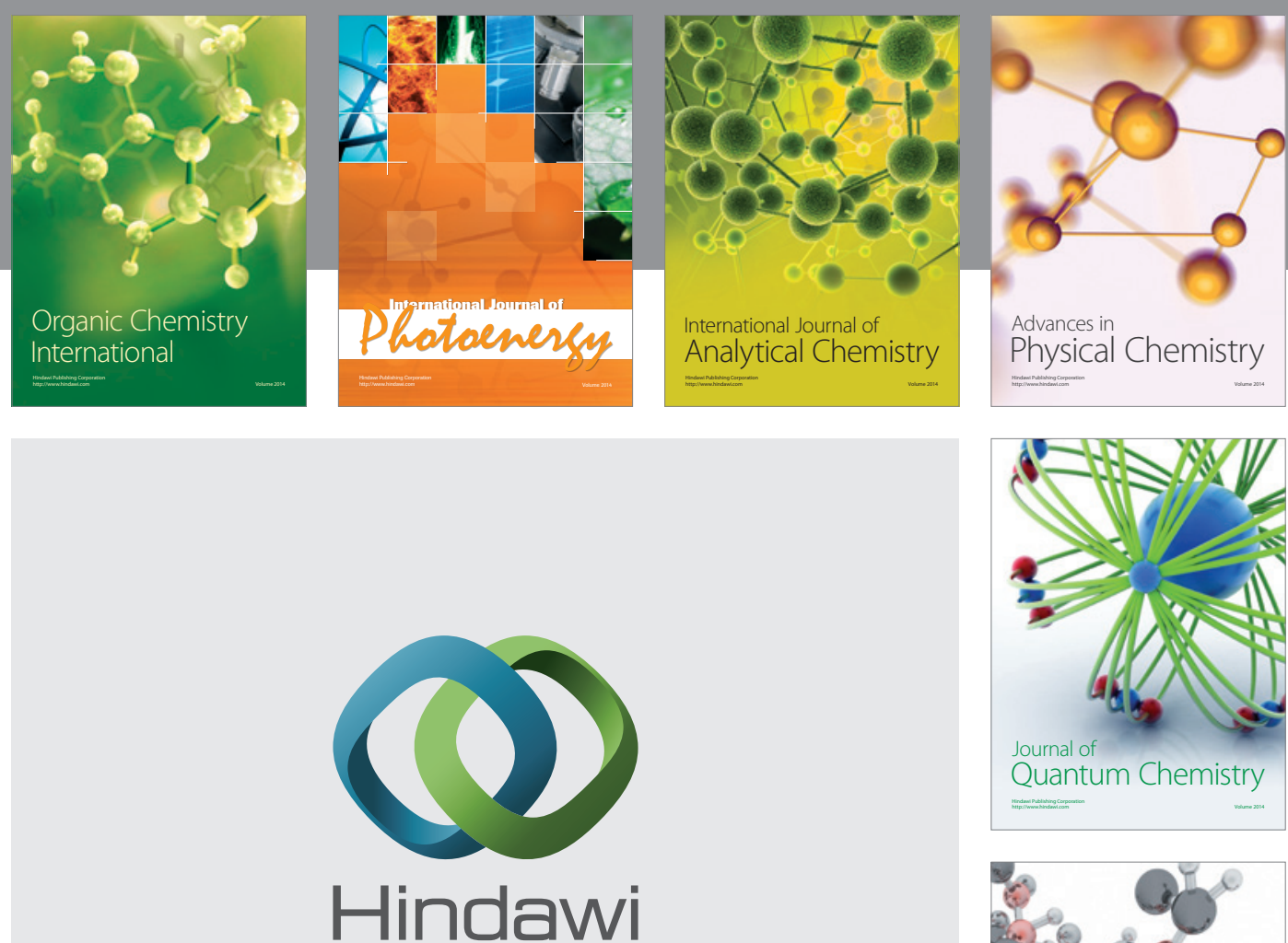

Submit your manuscripts at

http://www.hindawi.com

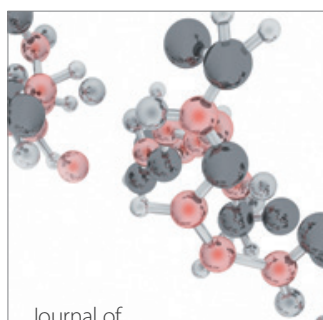

Analytical Methods

in Chemistry

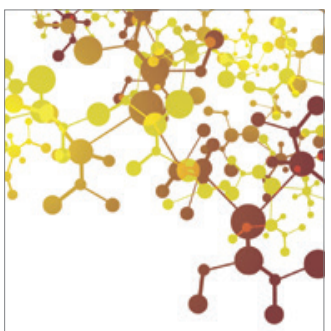

Journal of

Applied Chemistry

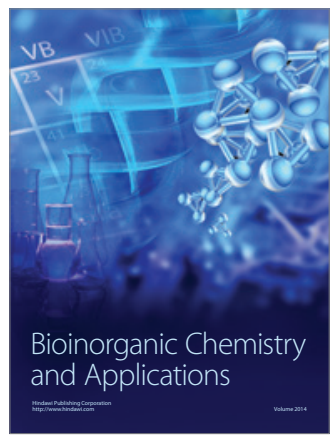

Inorganic Chemistry
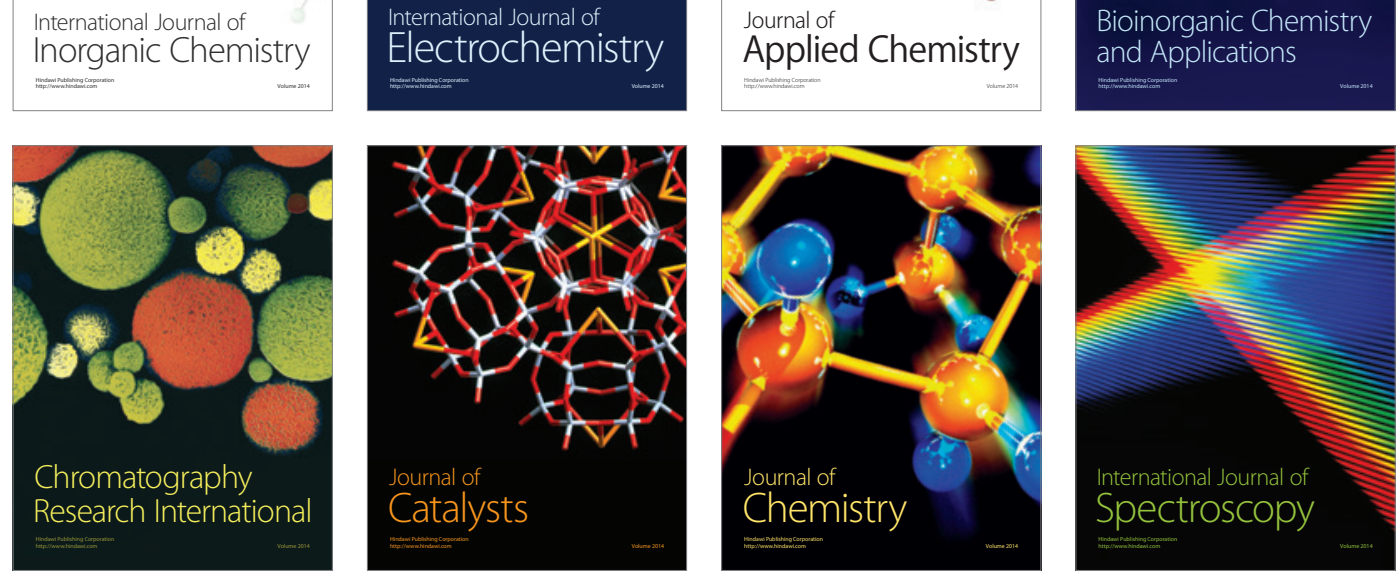